\title{
Ovulatory cycles and anovulatory periods in the addax (Addax nasomaculatus)
}

\author{
C. S. Asa, E. W. Houston, M. T. Fischer, J. E. Bauman, K. L. Bauman, \\ P. K. Hagberg and B. W. Read
}

St Lonis Zoological Park, St Lonis, MO 63110, USA

\begin{abstract}
Changes in serum oestradiol and progesterone were measured to study their dynamics during ovulatory cycles in six female addax, an endangered antelope. Blood was collected three times per week, during chute restraint, for 3 months (November to February) before introduction of a male, and continued until pregnancy was diagnosed with ultrasound. Serum was analysed by enzymeimmunoassay. Mean luteal phase, interluteal phase, and cycle durations were $22.7 \pm 2.0,8.78 \pm 0.5$ and $32.3 \pm 1.7$ days, respectively. Ultrasonography revealed coiled uterine horns and maximum follicle and corpus luteum diameters of 15 and $27 \mathrm{~mm}$, respectively. Each female experienced an anovulatory period, during which oestradiol continued to fluctuate, but progesterone remained below $2 \mathrm{ng} \mathrm{ml} \mathrm{m}^{-1}$. These periods ranged from 39 to 131 days and were not synchronous; ovulatory cycles resumed spontaneously in all females. All four females placed with a male conceived. Because addax give birth all year round, they are not considered seasonal breeders. The sporadic periods of anovulation that occurred during the winter months of this study suggest a possible seasonal effect. However, systematic sampling has not been conducted during summer and early autumn and will be necessary to address this question.
\end{abstract}

\section{Introduction}

The addax (Addax nasomaculatus) is a highly endangered, medium-sized spiral-horned antelope from the deserts of north Africa. Only 200-500 animals are believed to be left in the wild (Spevak et al,, 1993). Indiscriminate hunting, habitat degradation due to overgrazing by introduced livestock, the resulting introduction of livestock diseases, and several years of drought and political unrest within their native range have all combined to push this species to the brink of extinction (Correll, 1989). Yet, because these animals reproduce well and are easily managed in captivity (Fischer $e$ t al, 1993), there is real hope that a properly structured reintroduction programme, using as founder stock some of the more than 1700 addax in captivity worldwide (Correll, 1991), can replicate the success of a similar programme launched in the 1980 s on behalf of the Arabian oryx (Oryx leucoryx), a species exterminated from the wild in 1972 (Greth and Schwede, 1993; Spalton, 1993).

The reproductive behaviour of addax has been studied in some detail (Manski, 1991) and data have been compiled on several reproductive parameters using captive herd records (Densmore and Kraemer, 1986). Assisted reproduction techniques such as artificial insemination (AI) and embryo transfer could significantly enhance the genetic exchange necessary between managed captive addax populations and wild populations. Although AI has been used in addax on a very

Received 10 November 1995. limited basis (Densmore et al., 1987), the basic reproductive physiology and endocrinology of this species has not been studied in the detail necessary for effective use of these techniques. In particular, oestrous synchronization regimens based on domestic animal models have yielded disappointing results when applied to addax (Spevak et al, 1993), suggesting that the reproductive physiology of addax differs from that of the domestic cow.

The current study included two phases. Phase I consisted of 3 months during which no male was present so that successive cycles without conception could be characterized. During Phase II, a male was introduced to study mating behaviour and the endocrine events associated with conception and the possibility of pregnancy diagnosis via rectal ultrasound.

\section{Materials and Methods}

\section{Animals}

Age and parity of the six, sexually mature ( $>2$ years old) female addax used in the study are presented in Table 1 . Details of addax management at this facility have been reported by Fischer et al. (1993). Animals were given access to the $91.5 \mathrm{~m} \times 68.6 \mathrm{~m}$ outdoor yard at $08: 30 \mathrm{~h}$ or immediately after sample collection between $08: 30 \mathrm{~h}$ and $09: 30 \mathrm{~h}$. At $16: 30 \mathrm{~h}$ they were brought into two off-exhibit stalls (each $4.3 \mathrm{~m} \times 4.3 \mathrm{~m} \times 3 \mathrm{~m})$. At daytime ambient temperatures below $-7^{\circ} \mathrm{C}$ or during icy conditions, the animals were kept indoors. 
Table 1. Age and parity at study inception, and dates and durations of anovulatory periods in six female addax

\begin{tabular}{|c|c|c|c|c|c|}
\hline \multirow[b]{2}{*}{$\begin{array}{l}\text { Animal } \\
\text { number }\end{array}$} & \multirow[b]{2}{*}{$\begin{array}{c}\text { Age } \\
\text { (years) }\end{array}$} & \multicolumn{2}{|c|}{ Offspring } & \multicolumn{2}{|c|}{ Anovulatory periods } \\
\hline & & Number & Last parturition & Dates & $\begin{array}{c}\text { Duration } \\
\text { (days) }\end{array}$ \\
\hline 5 & 11 & 7 & Jan 1993 & 2 Mar-20 Jun 1994 & 110 \\
\hline 6 & 10 & 7 & Jan 1993 & 24 Nov 1993-4 Apr 1994 & 131 \\
\hline 12 & 7 & 3 & Feb 1993 & 12 Nov $1993^{*}-31$ Jan 1994 & 80 \\
\hline 26 & 5 & 0 & - & I Dec 1993-7 Apr 1994 & 127 \\
\hline 30 & 4 & 0 & - & 12 Nov $1993^{*}-23$ Mar 1994 & 131 \\
\hline 149 & 6 & $?$ & $?$ & 28 Mar-9 May 1994 & 39 \\
\hline
\end{tabular}

*First sampling day.

Indoor light was provided by a $0.3 \mathrm{~m} \times 0.3 \mathrm{~m}$ skylight and by fluorescent lights from $08: 30 \mathrm{~h}$ to $16: 30 \mathrm{~h}$. During winter months, the barn was maintained at $10^{\circ} \mathrm{C}$ by a forced-air gas furnace.

Mazuri ADF-16 Herbivore pellets (Purina Mills, St Louis, MO) and alfalfa hay were offered daily in a 50:50 ratio (by weight) indoors to encourage entry into the barn for morning sample collection. Occasionally an animal did not come in overnight.

\section{Behavioural observations}

The group was observed daily after introduction of the male to the herd on 26 February 1994 for courtship behaviours reported in Manski (1991): male laufschlag (foreleg lift), tandem circling, female urination, male flehmen, mounts, intromission and ejaculation. Observations were conducted from 08:30 h until 16:30 h from 26 February to 21 March and, thereafter, for periods of $2 \mathrm{~h}$ between 09:00 $\mathrm{h}$ and 12:00 h, and again between 13:00 $\mathrm{h}$ and 16:00 $\mathrm{h}$ each day. A time-lapse video cassette recorder and camera with infra-red lights were used to record behaviour indoors from $16: 30 \mathrm{~h}$ until $08: 30 \mathrm{~h}$. Video tapes were later reviewed for the same behaviours.

\section{Sample collection}

Animals were handled in a drop-floor cradle (The Tamer: Fauna Research Products, Red Hook, NY), described in detail in Read et al. (1993) and Fischer et al. (1993) with sides narrower at the bottom that are closed before the floor is dropped, leaving the animal suspended for handling through front and rear access doors. When sampling is completed, one side of the cradle can be slowly released, allowing the animal to gently slide to the ground. More than 1500 addax restraints have been successfully accomplished with this equipment at our facility.

After a period of acclimation, the addax were restrained for blood sampling three times per week for 3 months (Phase I: 10 November 1993 to 14 February 1994). For Phase II (26 February to 31 October 1994), a male was introduced to four of the females for mating (the others had been designated not to breed for reasons of genetic management). During Phase II, blood sampling continued and ultrasound examinations (Aloka
500V, 5.0 or $7.5 \mathrm{MHz}$ linear array transducer: Corometrics Medical Systems, Wallingford, CT) were instituted three times per week until pregnancy was confirmed. Thereafter, blood samples were collected and ultrasound examinations continued once a week. Ultrasound examination was accomplished by rectal insertion of the transducer, manipulated externally by stiff tubing secured around the cord to form a handle.

\section{Hormone assay}

Blood was centrifuged at $35 \mathrm{~g}$ for $10 \mathrm{~min}$ and serum stored at $-75^{\circ} \mathrm{C}$ until assay. Oestradiol and progesterone were quantitatively determined in unextracted serum samples using commercially available enzymeimmunoassay kits (Medix Biotech, Inc., San Carlos, CA). Assays were performed according to kit protocol with the exception that the primary incubation time for the oestradiol assay was increased from $3 \mathrm{~h}$ to a minimum of $48 \mathrm{~h}$ at room temperature which resulted in improved replicability. Calf serum (Sigma Chemical Co., St Louis, MO) was used as a diluent for progesterone samples with concentrations higher than the highest standard concentration and was found to have undetectable concentrations of progesterone.

The sensitivity of the assays, defined as twice the standard deviation of zero binding, was $13 \mathrm{pg} \mathrm{ml}^{-1}$ for oestradiol and $0.3 \mathrm{ng} \mathrm{ml} \mathrm{m}^{-1}$ for progesterone. All addax serum values fell between the lowest and highest standards. Known amounts of hormone were added to both addax serum (from juvenile males or early follicular phase females, expected to have low endogenous concentrations of both hormones) and calf serum at several different concentrations. Mean recoveries were as follows: oestradiol in addax serum $104.8 \pm 3.2 \%$, oestradiol in calf serum $103.2 \pm 2.4 \%$, progesterone in addax serum $103.5 \pm 2.2 \%$, and progesterone in calf serum $98.2 \pm 3.5 \%$ $(n=6)$.

When sera from pregnant addax (expected to have high concentrations of oestradiol and progesterone) was serially diluted in juvenile male addax serum, the resulting displacement curves were parallel to the standard curve in both assays. The following steroids showed crossreactivity as stated at $50 \%$ inhibition. Oestradiol assay: 16-ketoestradiol, 1.3\%; oestrone, 
Table 2. Intra- and interassay precision of oestradiol and progesterone enzymeimmunoassays as determined by replicability of quality control pools

\begin{tabular}{lccc}
\hline $\begin{array}{l}\text { Quality } \\
\text { control pool }\end{array}$ & $\begin{array}{c}\text { Percentage } \\
\text { inhibition* }\end{array}$ & $\begin{array}{c}\text { Intra-assay } \\
\text { CV }(\%)\end{array}$ & $\begin{array}{c}\text { Interassay } \\
\mathrm{CV}(\%)\end{array}$ \\
\hline Oestradiol & & & \\
Low & 27.0 & 15.1 & 7.9 \\
Medium & 49.2 & 4.2 & 3.9 \\
High & 65.6 & 5.0 & 4.5 \\
Progesterone & & & \\
Low & 26.8 & 21.0 & 14.0 \\
Medium & 49.8 & 5.3 & 4.7 \\
High & 73.2 & 6.3 & 5.6 \\
\hline
\end{tabular}

*Values given are means. $\mathrm{CV}$ : coefficient of variance.

$0.8 \%$; oestriol, $0.6 \%$; all others tested $\leq 0.5 \%$. Progesterone assay: $5 \alpha$-pregnane-3,20-dione ( $5 \alpha$-dihydroprogesterone), 7.6\%; 5 $\beta$-pregnan-3 $\alpha$-ol-20-one (pregnanolone), $3.4 \%$; 4-pregnen-17 $\alpha$-ol-3,20-dione (17 $\alpha$-hydroxyprogesterone), $2.1 \%$; all others tested $\leq 0.5 \%$ (Medix Biotech, Inc.).

Quality control serum at three concentrations was made from pooled addax serum, aliquoted, and frozen at $-75^{\circ} \mathrm{C}$ until use. Intra-assay precision was determined using six to eight replicates of quality control pools within an assay run, though not necessarily on the same assay plate, six times during a year. The coefficient of variation (CV) shown is the mean of individual CVs for each of the six assays. Interassay precision was determined by assaying the same pools in 18 consecutive assays (progesterone) or 21 consecutive assays (oestradiol) over a year (Table 2).

Because baseline concentrations of oestradiol were higher than seen in other bovids (domestic cow (Bos taurus): Henricks et al., 1971; domestic sheep (Ovis aries): Barrett et al., 1971; banteng (Bos javanicus): Asa et al., 1993a; Rocky Mountain goats (Oreamnos americanus): Asa et al, 1993b), serum samples were extracted with dextran-coated charcoal (DCC) to determine whether assayed values represented true steroid content or were raised as an artefact of the protein matrix. Three pools of addax serum with assayed oestradiol concentrations of $22.8,83.3$ and $163.6 \mathrm{pg} \mathrm{ml}^{-1}$ were extracted twice for $2 \mathrm{~h}$ at room temperature with $0.1 \mathrm{~g} \mathrm{DCC} \mathrm{ml}{ }^{-1}$ (activated charcoal, 100-400 mesh, stirred overnight at $4^{\circ} \mathrm{C}$ with $1 \%$ dextran MW 266 000; Sigma Chemical Co.), rinsed three times with distilled water and dried. Charcoal was removed from the serum by centrifugation at $14000 \mathrm{~g}$ for $10 \mathrm{~min}$. Recoveries of oestradiol by enzymeimmunoassay in the supernatants after the first extraction were $7.65,10.2$ and $11.9 \mathrm{pg} \mathrm{ml}^{-1}$, respectively. These concentrations were further reduced to $3.6,5.5$ and $5.4 \mathrm{pg} \mathrm{ml}^{-1}$ after the second DCC extraction, demonstrating that the assayed values represent true steroid content. (Concentrations were extrapolated below lowest standard.)

Assay results were transformed to log-logit plots for interpolation of unknown values. All samples were assayed in duplicate; if there was greater than 10\% variation between duplicates, the assays were repeated. For further assay validation, a subset of samples was assayed by radioimmuno- assay in another laboratory, using extraction and column chromatography. For 52 samples in which the concentrations fell within the limits of the standard curve in both laboratories, there was close correlation $\left(r^{2}=0.925\right)$ between assay values.

\section{Results}

Mean cycle duration (calculated from the first day of progesterone increase $\geq 2 \mathrm{ng} \mathrm{ml}^{-1}$ of one luteal phase to the first day of the next) was $32.3 \pm 1.7$ days for six cycles, four during Phase I and two during Phase II. Mean luteal phase duration (period during which progesterone remained $\geq 2 \mathrm{ng}$ $\mathrm{ml}^{-1}$ ) was $22.7 \pm 2.0$ days (four during Phase I and three during Phase II). Owing to the variability in oestradiol concentrations, the interval between luteal phases was calculated (using progesterone values $<2 \mathrm{ng} \mathrm{ml}^{-1}$ ) as an interluteal rather than a follicular phase. Of nine interluteal phases (five during Phase I and four during Phase II) the mean duration was $8.78 \pm 0.5$ days.

If sustained increases in progesterone $\geq 2 \mathrm{ng} \mathrm{ml}^{-1}$ are considered indicative of ovulation, all animals except one ( $n=30$ ) ovulated at least once during the study (see Figs 1 and 2). In contrast, all females displayed at least one period of apparent anovulation, characterized by fluctuating oestradiol concentrations with no detectable increases in progesterone (Table I; Figs Ib, c and $2 a, c$ ). These anovulatory periods varied in duration and occurred at different times of the year. All females placed with the male mated and conceived (Fig. 2), yet all had previously experienced anovulatory periods. Female 5 experienced an abortion, had one non-conceptive cycle, mated and conceived again (Fig. 2a). Female 6 died of causes unrelated to the study early in her pregnancy; the other three delivered healthy, full-term calves.

Results of ultrasound examinations varied, primarily owing to image distortion due to interference from faecal pellets. Although coils of the uterus could be detected reliably, ovaries were at times either beyond the range of the transducer or hidden by distortion from faecal pellets. Of the ovarian structures measured in this and in a pilot study in 1992-1993, maximum diameters of follicles and corpora lutea were 15 and $27 \mathrm{~mm}$, respectively. Representative images of ovaries with small or medium follicles and with a large, ovulatory follicle are presented (Figs 3 and 4, respectively).

Mating did not accompany ovulations after introduction of the male in late February through most of March, apparently because of the sexual inexperience of the male. Females solicited and the male appeared interested, evidenced by some circling and sniffing, but mounting with intromission did not occur until late March.

During behavioural observations, three of the four females that conceived were seen mating. Two females ( 6 and 12) were observed mating only during the night, between 17:00 $\mathrm{h}$ and 06:30 h. The other female (149) mated eight times during a $2 \mathrm{~h}$ watch between noon and 14:00 h. For these eight matings, laufschlag (1-56 times) preceded every mount, whereas circling preceded only two. From 29 March to I April, the oestrous phases of females 6 and 12 overlapped. On the night spanning 29 and 30 March, female 12 mated nine times. 

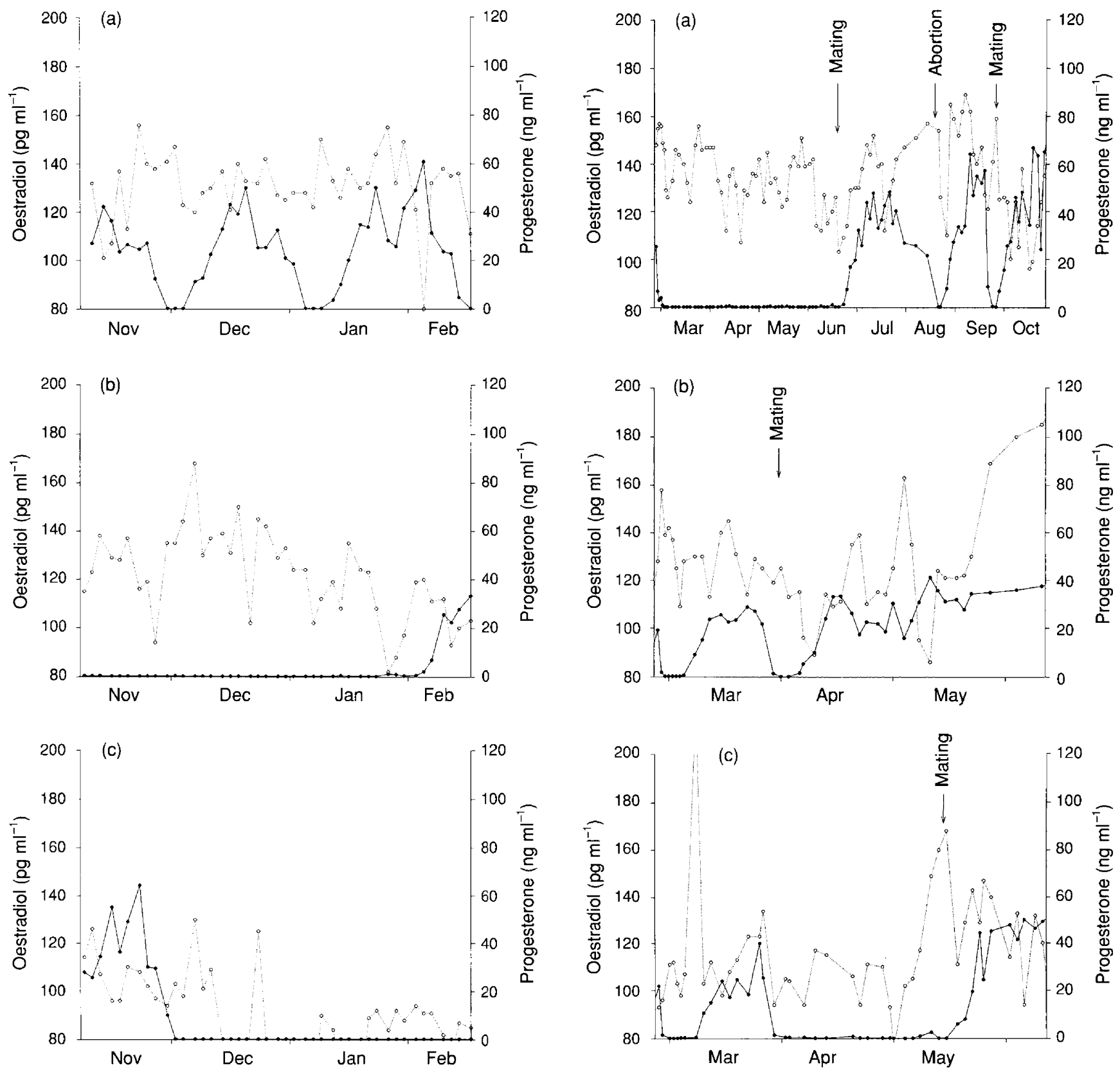

Fig. 1. Patterns of serum oestradiol $(O)$ and progesterone concentrations in three addax females when no male was present: (a) recurring ovulatory cycles, addax 5; (b) apparent anovulatory period followed by spontaneous resumption of ovulation, addax 12; (c) apparently normal luteal phase followed by an anovulatory period, addax 26 .

Circling and laufschlag preceded copulation $0-15$ times and 0-24 times, respectively. Female 6 mated once, preceded by 11 bouts of circling and 71 laufschlags during the previous hour. Each female was observed urinating once during this night, but the male displayed flehmen only to the urine of female 6 . During the following night, female 12 did not mate, but female 6 mated 13 times. Circling and laufschlag preceded copulation 0-11 times and 0-42 times, respectively. No other female urination or male flehmen was seen.

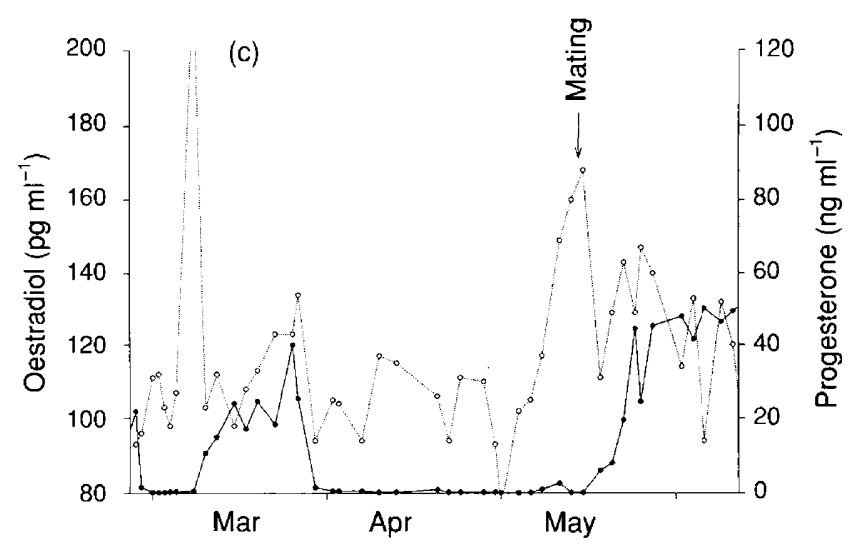

Fig. 2. Patterns of serum oestradiol (O) and progesterone (•) concentrations in three addax females when a male was present for mating: (a) anovulatory period followed by spontaneous resumption of ovulation with mating and conception, followed by abortion, an infertile cycle, and then mating and conception which resulted in live birth, addax 5; (b) mating and conception on the second cycle, followed by live birth, addax 12; (c) ovulation, anovulatory period, spontaneous resumption of ovulation accompanied by mating and conception, followed by live birth, addax 149 .

\section{Discussion}

Both the luteal and interluteal phases of the approximately 32 day ovulatory cycle of the addax are appreciably longer than those reported for other bovids, which have cycles of about 20 days (domestic cow, Bos taurus: Stabenfeldt et al., 1969; zebu, Bos indicus: Rakha et al., 1970; water buffalo, Bubalus bubalis: 


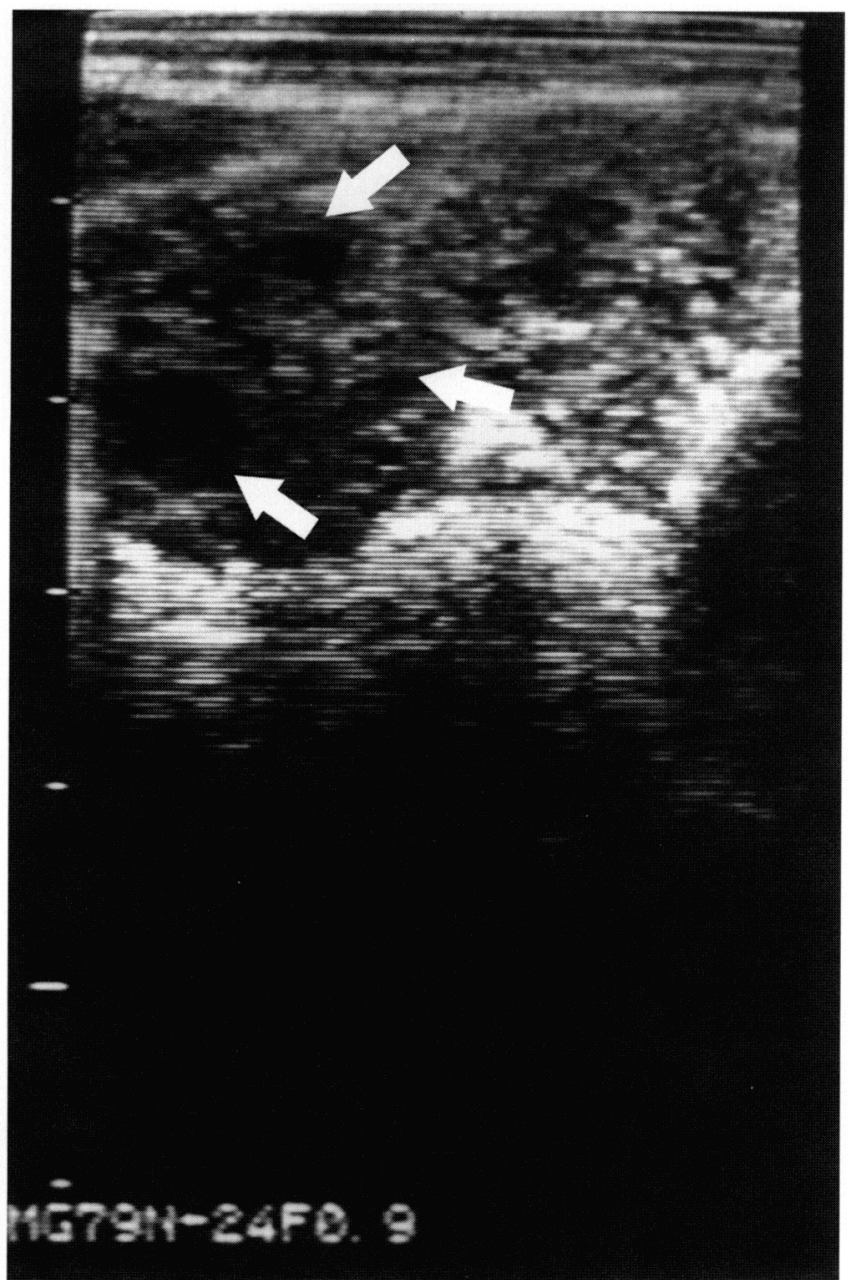

Fig. 3. Ultrasound image of addax ovary with follicles of $7 \mathrm{~mm}, 3 \mathrm{~mm}$ and several less than $3 \mathrm{~mm}$ diameter (arrows).

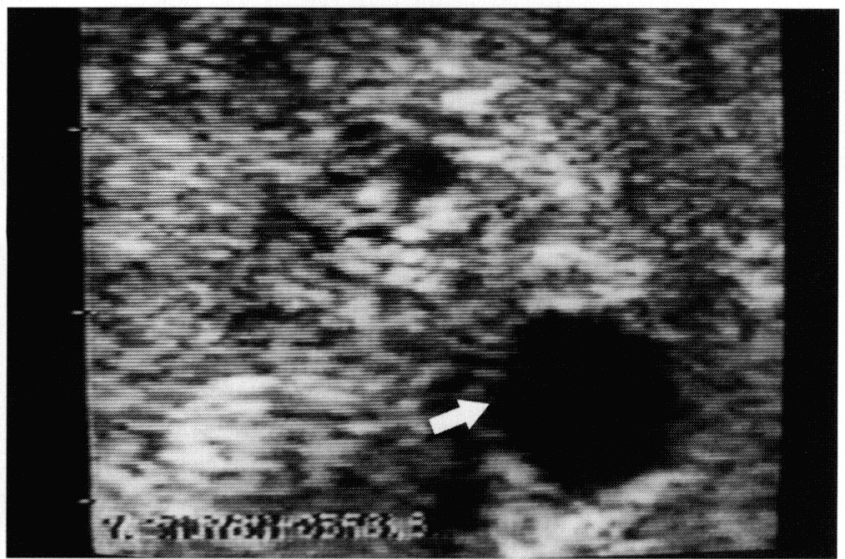

Fig. 4. Ultrasound image of addax ovary with ovulatory follicle (11 $\mathrm{mm} \times 9.4 \mathrm{~mm}$; arrow) on the day of mating.

Kanai and Shimizu, 1986; banteng, Bos javanicus: Asa et al., 1993a; muskoxen, Ovibus moschatus: Rowell and Flood, 1988). Cycle duration from faecal progestogen analysis was 24 days for oryx (Shaw et al., 1995). However, no comparable studies have been published for other antelope species.

More striking was the occurrence of irregular, nonsynchronous periods characterized by fluctuating oestradiol without detectable increases in progesterone. These patterns suggest that follicular growth occurred but was not followed by ovulation or luteinization. It is unclear whether this condition is analogous to the cystic follicles described for domestic cows (see Kesler and Garverick, 1982 for review). Possible explanations for the bovine cystic follicles include excess FSH overstimulating follicles, and deficiency in the synthesis or release of LH or GnRH. Unfortunately, sampling intervals were too great in this study for measurement of $\mathrm{LH}$ or $\mathrm{GnRH}$ to be of value

In addax in this study, the condition subsided spontaneously after various times. Ultrasound examination during these anovulatory periods revealed follicles of less than ovulatory size. All females, regardless of age or parity, experienced at least one anovulatory period during this study. No oestrous behaviour was displayed by the three females experiencing these apparently non-ovulatory periods when the male was present. The four females placed with the male for mating conceived. It is not known whether the abortion experienced by female 5 might have been related to the previous anovulatory period. However, she conceived during a subsequent cycle and gave birth to a healthy calf. Female 149 also conceived after an anovulatory period and carried the calf to term successfully.

Although the animals were housed together and maintained on the same diet, periods of anovulation were not synchronous, suggesting that variables such as temperature, photoperiod, or nutrients were not involved. Anovulatory periods did not appear to be related to dominance. Female 149, who was lowest in the hierarchy and presumably the most likely to experience cycle suppression, had the shortest anovulatory period.

Addax give birth all year round, and are not considered seasonal breeders. However, because this study was conducted from late autumn to early spring, it is not known whether the anovulatory periods occur seasonally or whether the failure is peripheral or central. Further work is necessary to explain this phenomenon and to determine whether it occurs in other species of antelope.

The authors thank E. D. Plotka, Marshfield Medical Research Center, Marshfield, WI, for radioimmunoassay of selected samples; G. London for assistance with videography; and hoofstock keepers for animal handling.

\section{References}

Asa CS, Read B, Houston EW, Gross T, Parfet J and Boever WJ (1993a) Serum estradiol and progesterone concentrations during the ovulatory cycle and pregnancy in banteng cattle (Bos javanicis) Theriogenology 39 1367-1376 Asa CS, Houston EW, Plotka ED, Lynch M and Jenness B (1993b) Patterns of serum estradiol and progesterone during the ovulatory cycle and pseudopregnancy in Rocky Mountain goats (Oreamnos americants) Joumal of Zow and Wildlife Medicine 24 190-195

Barrett S, Blockey MA de B, Brown JM, Cumming IA, Goding JR, Mole BJ and Obst JM (1971) Initiation of the oestrous cycle in the ewe by infusions of $\mathrm{PGF}_{2,}$, to the autotransplanted ovary Journal of Repreduction and Fertility. $\mathbf{2 4}$ I36-1.37 
Correll T (1989) The Addax Species Survival Plan Masterplan American Association of Zoos and Aquaria, Bethesda, MD

Correll T (1991) The International Studbook for Addax (Addax nasomaculatus) American Association of Zoos and Aquaria, Bethesda, MD

Densmore M and Kraemer D (1986) Analysis of reproductive data on the addax, Addax nasomaculatus, in captivity International Zoo Yearbook 24/25 303-306

Densmore M, Bowen JJ, Magyar SJ, Amos MS, Jr, Robinson RM, Harms PG and Kraemer DC (1987) Artificial insemination with frozen, thawed semen and pregnancy diagnosis in addax, Addax nasomaculatus Zoo Biology 6 21-29

Fischer MT, Houston EW and Read BW (1993) Management of addax (Addax nasomaculatus) at the St Louis Zoological Park. In Proceedings of the 1993 Regional Meeting of the American Association of Zoological Parks and Aquaria pp 548-555 Association of Zoos and Aquariums, Wheeling, West Virginia

Greth A and Schwede G (1993) The reintroduction programme for the Arabian oryx (Oryx leucoryx) in Saudia Arabia International Zoo Yearbook 32 73-80

Henricks DM, Dickey JF and Hill JR (1971) Plasma estrogen and progesterone levels in cows prior to and during estrus Endocrinology 89 1350-1355

Kenai $\mathrm{Y}$ and Shimizu $\mathbf{H}$ (1986) Changes in plasma concentrations of luteinizing hormone, progesterone and oestradiol-17 $\beta$ during the periovulatory period in cyclic swamp buffaloes (Bubalus bubalis) Animal Reproduction Science 11 $17-24$

Kesler DJ and Garverick HA (1982) Ovarian cysts in dairy cattle: a review Journal of Animal Science 55 1147-1159
Manski DA (1991) Reproductive behavior of addax antelope Applied Animal Behaviour Science 29 39-66

Rakha AM, Igboeli G and Hale D (1970) The oestrous cycle of Zebu and Sanga breeds of cattle in Central Africa journal of Reproduction and Fertility 23 411-414

Read BW, Williams B and Christman J (1993) Restraint devices for management and research procedures for ungulates International Zoo Yearbook $\mathbf{3 2}$ $148-154$

Rowell JE and Flood PF (1988) Progesterone, oestradiol-17ß, and LH during the oestrous cycle of muskoxen (Ovibos moschatus) Journal of Reproduction and Fertility 84 117-122

Shaw HJ, Green DI, Sainsbury AW and Holt WV (1995) Monitoring ovarian function in scimitar-horned oryx (Oryx dammah) by measurement of fecal 20a-progestagen metabolites Zoo Biology 14 239-250

Spalton A (1993) A brief history of the reintroduction of the Arabian oryx (Oryx leucoryx) into Oman 1980-1992 International Zoo Yearbook 32 $81-90$

Spevak EM, Blumer ES and Correll TL (1993) Species Survival Plan contributions to research and reintroduction of addax (Addax nasomaculatus) International Zoo Yearbook 32 9I-98

Stabenfeldt GH, Ewing LL and McDonald LE (1969) Peripheral plasma progesterone levels during the bovine oestrous cycle Journal of Reproduction and Fertility 19 433-442 